\title{
Tuberculous Meningitis during Chemotherapy for Advanced Gastric Cancer
}

\author{
Hiroshi Matsumoto ${ }^{a} \quad$ Akinori Sasaki $^{a}$ Yoshiaki Nakamura ${ }^{a}$ \\ Akihito Kawazoe $^{a}$ Yasutoshi Kuboki ${ }^{a}$ Keiji Okinakab Kohei Shitara ${ }^{a}$ \\ ${ }^{a}$ Department of Gastroenterology and Gastrointestinal Oncology, National Cancer Center \\ Hospital East, Kashiwa, Japan; bDepartment of General Medicine and Infectious Diseases, \\ National Cancer Center Hospital East, Kashiwa, Japan
}

\section{Keywords}

Gastric cancer · Tuberculous meningitis · Chemotherapy · Paclitaxel

\begin{abstract}
Introduction: Tuberculous meningitis is rare but one of the most severe forms of tuberculosis infection. Case Report: A 78-year-old woman was diagnosed with advanced gastric cancer with multiple lymph node metastases. Four months after the beginning of second-line chemotherapy with weekly paclitaxel, she was admitted to our hospital because of fever and mild drowsiness. She had no other symptoms and no abnormalities in physical examinations. Her blood tests, urinalysis, and blood culture revealed no remarkable abnormal findings. Although her symptoms relieved, her disturbance of consciousness gradually progressed during 2 weeks thereafter. Finally, we diagnosed tuberculous meningitis on the 22nd day of hospitalization by a positive acid-fast bacilli test of the cerebrospinal fluid and tuberculosispolymerase chain reaction. Although anti-tuberculosis therapy was started, she died on the 37th day of hospitalization because of tumor bleeding. Conclusion: To the best of our knowledge, this is the first report of tuberculous meningitis during chemotherapy for ad-
\end{abstract}




\section{Case Reports in Oncology}

\begin{tabular}{l|l} 
Case Rep Oncol 2018;11:228-233 \\
\hline DOI: 10.1159/000488313 & $\begin{array}{l}\text { @ 2018 The Author(s). Published by S. Karger AG, Basel } \\
\text { www.karger.com/cro }\end{array}$
\end{tabular}

Matsumoto et al.: Tuberculous Meningitis during Chemotherapy for Advanced Gastric Cancer

vanced gastric cancer, suggesting that subacute onset of fever followed by disturbance of consciousness may indicate the possibility of tuberculous meningitis even without typical signs of meningitis including headache or meningeal irritation.

(C) 2018 The Author(s)

Published by S. Karger AG, Basel

\section{Introduction}

Tuberculous meningitis is a rare disease that has an extremely poor prognosis $[1,2]$. It is one of the most severe forms of tuberculosis infections, for which early intervention is important to improve treatment outcomes [3]; however, subacute and nonspecific clinical features as well as insensitive laboratory tests complicate early diagnosis [4]. Here, we report a case of tuberculous meningitis, which developed during chemotherapy for gastric cancer.

\section{Case Presentation}

A 78-year-old woman was diagnosed with advanced gastric cancer with multiple lymph node metastases in January 2017. She received second-line chemotherapy with ramucirumab plus paclitaxel starting in August 2017 after failure of first-line chemotherapy. Because of complications with gastrointestinal hemorrhage due to primary gastric tumor, weekly paclitaxel monotherapy was continued from October 2017, which achieved stable disease. Four months after the beginning of second-line chemotherapy and 1 week before hospitalization, she was febrile with a temperature of $38.0^{\circ} \mathrm{C}$ and consulted the outpatient department. She presented with no accompanying symptoms other than fever and showed no abnormalities in physical examinations. Moreover, her complete blood count tests, serum chemistry, urinalysis, and blood culture revealed no significant findings; therefore, she was discharged home with oral antipyretics. However, 4 days later, she was febrile again with a temperature of $39.8^{\circ} \mathrm{C}$ along with drowsiness and was admitted to our hospital. After admission, she almost returned to full consciousness without headache and meningeal irritation signs. A computed tomography (CT) scan did not identify a significant abnormality in the brain but revealed an emerging small infiltration in the right upper lung lobe as a possible cause of the fever. She was empirically treated with piperacillin/tazobactam for possible bacterial pneumonia. Her fever gradually improved up to the 7th day of hospitalization; however, thereafter, her mild disturbance of consciousness in the form of delirium was worsening and a fever of $38-39^{\circ} \mathrm{C}$ was once again observed around the 10th day of hospitalization. Her disturbance of consciousness finally progressed to drowsiness by the 14th day of hospitalization. A brain CT scan on the 14th day revealed apparent ventricular enlargement and periventricular edematous changes compared with that on admission (Fig. 1). Cerebrospinal fluid was collected through a lumbar puncture, which showed a significant increase in the number of mononuclear cells (Table 1). Due to her accompanying advanced gastric cancer, meningitis carcinomatosis was first suspected, for which dexamethasone (6.6 $\mathrm{mg} /$ day) treatment was initiated while waiting for cytology results. However, her disturb- 


\section{Case Reports in Oncology}

Case Rep Oncol 2018;11:228-233

DOI: $10.1159 / 000488313$

(C) 2018 The Author(s). Published by S. Karger AG, Basel www.karger.com/cro

Matsumoto et al.: Tuberculous Meningitis during Chemotherapy for Advanced Gastric Cancer

ance of consciousness persisted and deteriorated further, and another cerebrospinal fluid test was performed on the 19th day of hospitalization because of negative cytology results in the first investigation. A significant increase in polynuclear cell numbers and overall cell counts as well as a decrease in the glucose content of the cerebrospinal fluid was noted (Table 1). The cerebrospinal fluid samples were submitted for bacterial, mycobacterial, and fungal cultures. An acid-fast bacilli test of the cerebrospinal fluid was negative, but we initiated empirical anti-tuberculosis treatment since tuberculous meningitis could not be excluded with subacute onset of symptoms. On the 22nd day of hospitalization, positive tuberculosis-polymerase chain reaction (TB-PCR) of the cerebrospinal fluid confirmed the diagnosis of tuberculous meningitis. Her sputum tested was also positive on TB-PCR. Because oral medication was not possible, a triple-drug combination therapy consisting of isoniazid, levofloxacin, and streptomycin was initiated. She continued to receive anti-tuberculosis treatment, and her state of consciousness temporarily improved. Unfortunately, she died on the 37 th day of hospitalization due to gastrointestinal bleeding from the gastric cancer.

\section{Discussion}

Tuberculosis remains the 9th leading cause of death globally, with 1.3 million HIVnegative patients dying from tuberculosis in 2016. This disease is mainly prevalent in developing countries [5]. Meanwhile, in developed countries, advances of anti-tuberculosis medication and infection control measures have resulted in a decline in its incidence, but the prevalence rate of tuberculosis in Japan is still higher than in Western countries: the official estimate of incidence of tuberculous in Japan was about 13.9 per 100,000 population in 2016 [6]. Tuberculous meningitis is a particularly rare disease, with an incidence rate of 100-150 cases annually in the United States, which accounts for approximately $3 \%$ of all cases of infective meningitis and about 162 cases annually in Japan $[1,7]$. The primary cause of tuberculous meningitis is reactivation due to impaired immune function, which can be attributed to aging, alcoholism, diabetes, recent steroid use, HIV infection, and other factors. Cases of concomitant malignant tumors have also been reported in a previous study [8], although, to the best of our knowledge, there was no previously reported case during chemotherapy for advanced gastric cancer.

Compared with aseptic meningitis or typical bacterial meningitis, tuberculous meningitis has subacute progression and in many cases, it does not initially present with headaches or typical signs of meningeal irritation, such as neck stiffness [4]. At the early stage of onset, patients often present only with nonspecific symptoms, such as fever, loss of appetite, and fatigue, which makes early diagnosis difficult, as shown in our patient. As the disease progresses to the subacute stage, behavioral changes, drowsiness, and irritability appear and the patient gradually presents with the classic symptoms of meningitis, such as headaches, vomiting, reduced level of consciousness, meningeal irritation, and cranial nerve palsy [9]. The exact timing of disease onset was unclear in our patient, but her symptoms were limited to fever and drowsiness before admission, which are nonspecific symptoms especially in advanced cancer patients. A previous report suggested several clues to diagnose tuberculous meningitis [10]. Regarding the definitive diagnosis of Mycobacterium tuberculosis infection, a smear or culture of the cerebrospinal fluid with acid-fast bacillus staining has been found to 
show high specificity but a low detection sensitivity of $10-37 \%$ with smear and $43-52 \%$ with culture [11-13]. The long 4- to 8-week wait in the culturing method is also a disadvantage. The detection of $M$. tuberculosis gene by PCR is comparatively much faster, with a sensitivity of $60-90 \%$ and a specificity of $89-100 \%$ [14]. The timing of treatment initiation has a major impact on a patient's prognosis [3]. Therefore, not only definitive diagnosis by these tests but also probable tuberculous meningitis based on scoring clinical criteria or cerebral imaging criteria were proposed [10] to initiate empirical treatment, which might have potentially accelerated treatment in our patient.

To the best of our knowledge, this is the first report of tuberculous meningitis during chemotherapy for advanced gastric cancer. It should be noted that subacute onset of fever followed by nonspecific neurological findings, such as disturbance of consciousness, indicate the possibility of tuberculous meningitis even without typical signs including headache or meningeal irritation. Empirical therapy should be discussed based on clinical diagnosis.

\section{Statement of Ethics}

The authors have no ethical conflicts to disclose.

\section{Disclosure Statement}

All authors declare that there is no conflict of interest regarding the publication of this paper.

\section{References}

1 Marx GE, Chan ED. Tuberculous meningitis: diagnosis and treatment overview. Tuberc Res Treat. 2011;2011:798764.

2 Kamei S, Takasu T. Nationwide survey of the annual prevalence of viral and other neurological infections in Japanese inpatients. Intern Med. 2000 Nov;39(11):894-900.

3 Rodrigues MG, Lin J, Masruha MR, Vilanova LC, Minett TS. Prognostic factors predicting a fatal outcome in HIV-negative children with neurotuberculosis. Arq Neuropsiquiatr. 2010 Oct;68(5):755-60.

4 Thwaites GE, van Toorn R, Schoeman J. Tuberculous meningitis: more questions, still too few answers. Lancet Neurol. 2013 Oct;12(10):999-1010.

$5 \quad$ WHO Global Tuberculosis Report 2017.

6 Infectious Agents Surveillance Report (IASR). 2017, vol 38, pp 231-2. Available from: https://www.niid.go.jp/niid/ja/tuberculosis-m/tuberculosis-iasrtpc/7725-454t.html.

7 Tuberculosis Surveillance Center RIT JATA. Tuberculosis annual report 2009. Series 1 . Summary of TB notification statistics in 2009. Kekkaku. $2011 \mathrm{Feb}$;6(2):127-30. Japanese.

8 Berenguer J, Moreno S, Laguna F, Vicente T, Adrados M, Ortega A et al. Tuberculous meningitis in patients infected with the human immunodeficiency virus. N Engl J Med. 1992 Mar;326(10):668-72.

9 Rodrigues MG, da Rocha AJ, Masruha MR, Minett TS. Neurotuberculosis: an overview. Cent Nerv Syst Agents Med Chem. 2011 Dec;11(4):246-60.

10 Marais S, Thwaites G, Schoeman JF, Török ME, Misra UK, Prasad K et al. Tuberculous meningitis: a uniform case definition for use in clinical research. Lancet Infect Dis. 2010 Nov;10(11):803-12.

11 Verdon R, Chevret S, Laissy JP, Wolff M. Tuberculous meningitis in adults: review of 48 cases. Clin Infect Dis. 1996 Jun;22(6):982-8. 


\section{Case Reports in Oncology}

\begin{tabular}{l|l}
\hline Case Rep Oncol 2018;11:228-233 \\
\hline DOI: 10.1159/000488313 & $\begin{array}{l}\text { @ 2018 The Author(s). Published by S. Karger AG, Basel } \\
\text { www.karger.com/cro }\end{array}$
\end{tabular}

Matsumoto et al.: Tuberculous Meningitis during Chemotherapy for Advanced Gastric Cancer

12 Thwaites G, Chau TT, Mai NT, Drobniewski F, McAdam K, Farrar J. Tuberculous meningitis. J Neurol Neurosurg Psychiatry. 2000 Mar;68(3):289-99.

13 Kennedy DH, Fallon RJ. Tuberculous meningitis. JAMA. 1979 Jan;241(3):264-8.

14 Takahashi T, Tamura M, Takasu T. The PCR-Based Diagnosis of Central Nervous System Tuberculosis: up to Date. Tuberc Res Treat. 2012;2012:831292.
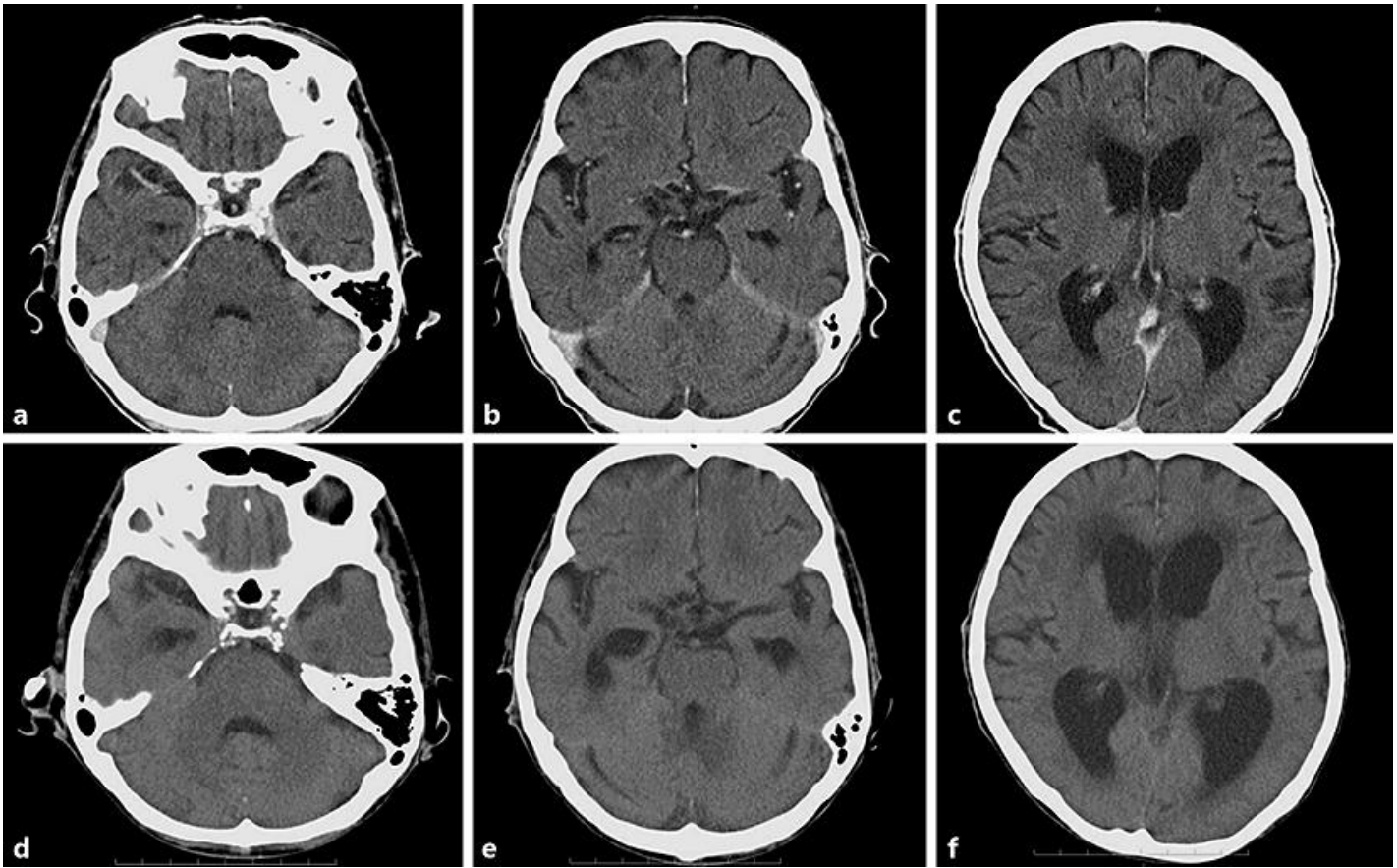

Fig. 1. Findings on head CT scans. a-c Head CT scans at the time of admission are within normal range considering the patient's age. $\mathbf{d}-\mathbf{f}$ Head CT scans on the 14th day of hospitalization. Clear ventricular enlargement and periventricular edematous changes are seen compared with those at the time of admission. 


\section{Case Reports in Oncology}

\begin{tabular}{l|l}
\hline Case Rep Oncol 2018;11:228-233 \\
\hline DOI: 10.1159/000488313 & $\begin{array}{l}\text { (c) 2018 The Author(s). Published by S. Karger AG, Basel } \\
\text { www.karger.com/cro }\end{array}$
\end{tabular}

Matsumoto et al.: Tuberculous Meningitis during Chemotherapy for Advanced Gastric Cancer

Table 1. Blood tests and cerebrospinal fluid tests during admission

\begin{tabular}{llll}
\hline & Day 1 & Day 14 & Day 19 \\
\hline Blood tests & & & \\
White blood cell count, $/ \mu \mathrm{L}$ & 8,600 & 12,200 & 19,800 \\
Red blood cell count, $\times 10^{4} / \mu \mathrm{L}$ & 357 & 390 & 303 \\
Hemoglobin, $\mathrm{g} / \mathrm{dL}$ & 10.6 & 11.6 & 9.1 \\
Platelet count, $\times 10^{4} / \mu \mathrm{L}$ & 60.8 & 29.4 & 21.1 \\
C-reactive $\mathrm{protein}, \mathrm{mg} / \mathrm{dL}$ & 1.34 & 0.14 & 8.08 \\
Sodium, $\mathrm{mEq} / \mathrm{L}$ & 130 & 136 & 155 \\
Potassium, mEq/L & 3.8 & 3.3 & 3.7 \\
Chloride, $\mathrm{mEq} / \mathrm{L}$ & 90 & 94 & 115 \\
Creatinine, $\mathrm{mg} / \mathrm{dL}$ & 0.53 & 0.37 & 0.34 \\
Urea nitrogen, mg/dL & 6.3 & 23.9 & 38.6 \\
Glucose, mg/dL & 110 & 129 & 173 \\
\hline Cerebrospinal fluid tests & & & \\
Cell count, $/ \mu \mathrm{L}$ & & 283 & 1,140 \\
Mononuclear cells, $/ \mu \mathrm{L}$ & & 37 & 775 \\
Polymorphonuclear cells, $/ \mu \mathrm{L}$ & & 246 & 366 \\
Protein, mg/dL & & 260 & 459 \\
Glucose, $\mathrm{mg} / \mathrm{dL}$ & 54 & 30 \\
\hline
\end{tabular}

